\title{
Comparative Study of the Geomagnetic Activity Effect on foF2 Variation as Defined by the Two Classification Methods at Dakar Station over Solar Cycle Phases
}

\author{
Sibri Alphonse Sandwidi, Doua Allain Gnabahou ${ }^{\circledR}$, Frédéric Ouattara* \\ Laboratoire de Recherche en Energétique et Météorologie de l'Espace (LAREME) de l'Université Norbert ZONGO, Koudougou, \\ Burkina Faso \\ Email: *fojals@yahoo.fr
}

How to cite this paper: Sandwidi, S.A., Gnabahou, D.A. and Ouattara, F. (2020) Comparative Study of the Geomagnetic Activity Effect on foF2 Variation as Defined by the Two Classification Methods at Dakar Station over Solar Cycle Phases. International Journal of Geosciences, 11, 501-517.

https://doi.org/10.4236/ijg.2020.118026

Received: July 3, 2020

Accepted: August 14, 2020

Published: August 17, 2020

Copyright $\odot 2020$ by author(s) and Scientific Research Publishing Inc. This work is licensed under the Creative Commons Attribution International License (CC BY 4.0).

http://creativecommons.org/licenses/by/4.0/

\begin{abstract}
This paper aims to establish a comparison between both geomagnetic activity classification methods on foF2 diurnal variation over solar cycle phases. It concerns first a comparison of geomagnetic activity occurrences according to both classification methods; and second the geomagnetic effect on foF2 diurnal variation profiles as defined for the equatorial latitudes. The occurrences of the different disturbed geomagnetic activities (recurrent activity (RA), shock activity (SA) and fluctuant activity (FA)) according to both classifications (ancient classification (AC) and new classification (NC)) have been studied at Dakar ionosonde station (Lat: $14.8^{\circ} \mathrm{N}$; Long: $342.6^{\circ} \mathrm{E}$ ). Regarding both classifications, the RA occurs more during the decreasing phase. And it's observed that the RA occurs the most during the increasing phase for the AC and during the minimum phase for the NC. The maximum gap of occurrence ( $\Delta_{\text {occ }}$ ) between both classifications is $-11.1 \%$ (for the negative value which is observed during the increasing phase) and $+16.74 \%$ (for the positive one which is observed during the decreasing phase). The occurrence of the SA in relation with both classifications is the lowest during the minimum phase and the maximum occurrence is observed during the maximum and decreasing phases, for the AC, with a value close to $37 \%$ and for the $\mathrm{NC}$ at the maximum phase with a percentage of $54.47 \%$. The maximum gap of occurrence $\left(\Delta_{\text {occ }}\right)$ between both classifications is $-17.85 \%$ (for the negative value which is observed at maximum phase) and $+13.53 \%$ (for the positive one which is observed during the decreasing phase). For both classifications, the FA occurs the least during the minimum phase and the most during the maximum phase for the $\mathrm{AC}$ and at maximum and decreasing phases with percentage
\end{abstract}


values of occurrence of roughly $37 \%$ for the NC. The maximum gap of occurrence $\left(\Delta_{\text {occ }}\right.$ ) between both classifications is $-10 \%$ (for the negative value which is observed during the decreasing phase) and $+20.11 \%$ (for the positive one which is observed during the maximum phase). foF2 diurnal profiles throughout solar cycle phases concerning the AC and the NC have been compared. The FA diurnal profiles don't present a difference. The RA and the SA present a difference during minimum and increasing phases and the least at maximum and decreasing phases.

\section{Keywords}

Geomagnetic Activity Classification Method, Solar Cycle Phases, foF2

Diurnal Profile

\section{Introduction}

The irradiation of the Earth space environment by the magnetized plasma propagating from the Sun induced a continuous global magnetic disturbance, namely geomagnetic storms [1]. In fact, the Sun magnetic field interacts with the Interplanetary Magnetic Field (IMF) by means of its two components: 1) the poloidal magnetic field which is closed and responsible of the Coronal Mass Ejections (CMEs), the magnetic clouds and high stream solar wind, 2) the toroidal magnetic field named sunspot activities which is the source of slow solar wind [1] [2] [3] [4] [5].

This Sun-Earth interaction is characterized by four geomagnetic events identified by [1] by using: 1) the geomagnetic aa index carried out by [6] [7] [8] [9], 2) the date of Sudden Storm Commencement (SSC) and 3) the correlation existing between the geomagnetic aa index and the solar wind speed established by Svalgaard [10]. The same number of geomagnetic activity has been found by Richardson et al. [2] [3] [4], but they named the fluctuating activity as the unclear activity which characterized the cases where the solar mechanisms cannot be clearly identified. This classification gives only $60 \%$ of the geomagnetic activities solar sources clarification.

Zerbo et al. [11] established a new classification criterion which clarifies about $80 \%$ of the geomagnetic activities solar sources by lowering the limit of the aa index for the shock and recurrent events and adding other causes from solar activity. Then the two schemes are different only for the disturbed geomagnetic activities. This paper deals with the comparison of the both classifications critical frequency of the ionosphere F2 layer (foF2) diurnal profiles as measured at Dakar ionosonde station (Lat: $14.8^{\circ} \mathrm{N}$; Long: $342.6^{\circ} \mathrm{E}$; dip: +5.53 ).

Several papers (e.g. [12]-[23]) have been carried out in African Equatorial Ionization Anomaly (EIA) sector about the morphological studies of the foF 2 profiles by using Legrand and Simon classification. Here, we focus our attention to a comparison of the both classification profiles over solar cycle phases on the F2 
layer critical frequency (foF2) time variation at Dakar station. The novelty of this study appears as it is a first paper where such comparison is made for the two classification methods. This paper aims, in short term, to highlight how the signature of the storm effect is shown by the geomagnetic events of the both classification methods and in mean and long term to contribute to improve the understanding of the sources of geomagnetic activities.

The outline of the paper is as follows: Section 2 concerns materials and methods, Section 3 is devoted to results and discussions, and the conclusion and research perspectives end the paper as its fourth section.

\section{Data and Methods}

\subsection{Data}

For the present paper, data involved are: 1) foF2 values carried out at Dakar station. This station operated from 1950 to December 1996. The involved data interval for our study is 1976-1995 and concerned Solar Cycle 21 (SC 21) and Solar Cycle 22 (SC 22); 2) Zurich sunspot number (Rz), from OMNI data set http://omniweb.gsfc.nasa.gov/form/dx1.html. For the influence of solar cycle phase and 3) Mayaud [6] [7] [8] [9] geomagnetic index aa for geomagnetic activity impacts. For this study, foF2 diurnal variation is analyzed by considering seasonal impacts. The seasons are considered here are: 1) spring (March, April and May); 2) summer (June, July and August); 3) autumn (September, October and November); and 4) winter (December, January and February).

\subsection{Methods}

\subsubsection{Criteria for Solar Cycle Phase Determination}

Solar cycle phases are determined by using the criteria given by [24]-[30]: 1) minimum phase: $\mathrm{Rz}<20$, where $\mathrm{Rz}$ is the yearly average Zürich Sunspot number; 2) ascending phase: $20 \leq \mathrm{Rz} \leq 100$ and $\mathrm{Rz}$ greater than the previous year's value; 3) maximum phase: $\mathrm{Rz}>100$ [for small solar cycles (solar cycles with Sunspot number maximum (Rzmax) less than 100), the maximum phase is obtained by considering $\mathrm{Rz}>0.8 \times$ Rzmax]; and 4) descending phase: $100 \geq \mathrm{Rz} \geq$ 20 and $\mathrm{Rz}$ less than the previous year's values.

\subsubsection{Description of the Two Geomagnetic Activity Classification Methods}

Based on the strong correlation between geomagnetic index Aa (obtained from the following website: http://isgi.unistra.fr/data_download.php) and solar wind velocity established by [1] and [10] described criteria for geomagnetic activity classification like this: 1) quiet activity (QA) are characterized by $\mathrm{Aa}<20 \mathrm{nT}$, very quiet activity (VQA) by $\mathrm{Aa}<10 \mathrm{nT}$ and 2) disturbed activities by $\mathrm{Aa} \geq 20$ $\mathrm{nT}$ arranged in three groups such as: 1) recurrent activity (RA) due to solar high wind stream coming from coronal holes with $\mathrm{Aa} \geq 40 \mathrm{nT} ; 2$ ) shock activity (SA) due to Coronal Mass Ejections (CMEs) with $\mathrm{Aa} \geq 40 \mathrm{nT}$ and 3) fluctuating activity (FA), consequences of the fluctuation of solar heliosheet. 
It's important to note that, this Legrand and Simon's classification or ancient classification (AC) clearly classify only $60 \%$ of the geomagnetic activity [1] [11] [25] [26] [31] [32] whereas the scheme proposed by Zerbo et al. [11] allows to clearly classify $80 \%$ of the geomagnetic activity. The new classification is characterized by: 1) the same limit with the first classification for the quiet activity (Aa $<20 \mathrm{nT}$ ) and 2) the lowering of the limit ( $\mathrm{Aa} \geq 20 \mathrm{nT}$ ) for the shock and recurrent events for whom the causes from solar activity are more highlighted [11]. Therefore: 1) recurrent activities (RA), characterised by $\mathrm{Aa} \geq 20 \mathrm{nT}$, are now the recurrent activity of Legrand and Simon plus the Corotative Moderate Activity (CMA) and they are due to solar high wind stream and Corotating interaction Region (CIRs); 2) shock activities (SA) are now the shock activity of Legrand and Simon plus the Cloud Shock Activity (CSA) and they are caused by Coronal Mass Ejections (CMEs) and magnetic clouds, respectively, with $\mathrm{Aa} \geq 20 \mathrm{nT}$ and 3) fluctuating activities (FA) or unclear events represent the fluctuating activity of Legrand and Simon plus the Corotating Moderate Activity (CMA); they are consequences of the fluctuation of solar heliosheet. This paper thus concerns the comparison between the profiles of foF 2 daily variation during disturbed activities of both schemes of geomagnetic activity classification as described.

The pixel diagram presents the variation of the geomagnetic activity by solar rotation, also called Bartels rotation [12] [13] [16] [17] [18] [19] [20] [22] [23] [33] [34]. It shows per year an overview of the whole solar geoeffectiveness activity (each type of the solar wind activity [slow, recurrent, CIRs and fluctuating winds activity] and that of CMEs and magnetic clouds [19]. This colour board is used to determine the geomagnetic data as a function of solar activity as described by solar rotation duration (27 days) which consists of: 1 ) plotting the aa daily values in Bartels diagrams, 2) exhibiting the different types of geomagnetic activities as described above according to both criteria. Figure 1 showed the pixel diagram highlighting the process to determine the different geomagnetic activities following the criteria of the two methods of classification.

\subsubsection{Data Analysis Method}

This paper aims to study the difference of foF2 time variation, throughout solar cycle phases for a given disturbed activity for the both geomagnetic activity classifications. The data analysis will be done through two ways: 1) The analysis of the recurrence of the different geomagnetic activities according to the both methods of classification over solar cycle phases in one case and seasons in another case; 2) The profiles obtained are analyzed in comparison with the five standard profiles established by [35] for African Equatorial Ionization Anomaly (EIA) region and 3) the quantitative analysis based on comparison between foF2 profiles from both classifications methods.

Firstly, the analysis of the occurrence of the geomagnetic activities is done by: 1) comparing the occurrence of the different geomagnetic activities in relation with the both classification by using the Equation (1);

$$
\Delta_{\text {occ }}=\mathrm{GA}_{\mathrm{occ}} / \mathrm{AC}-\mathrm{GA}_{\mathrm{occ}} / \mathrm{NC}
$$




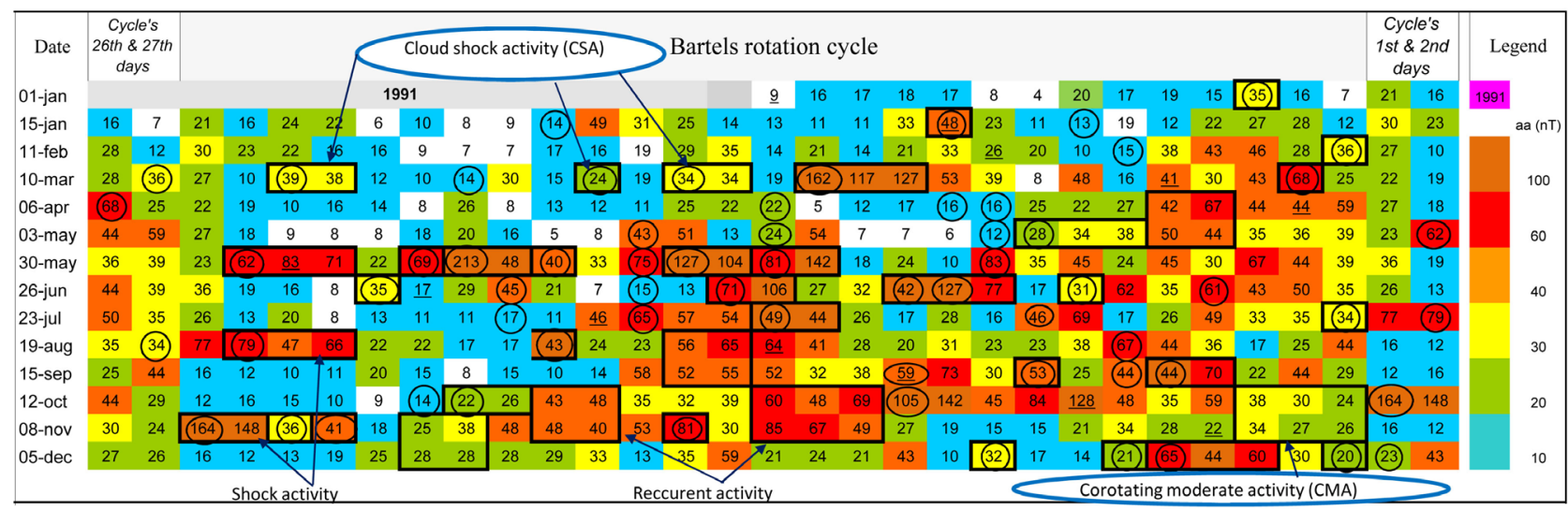

(a)

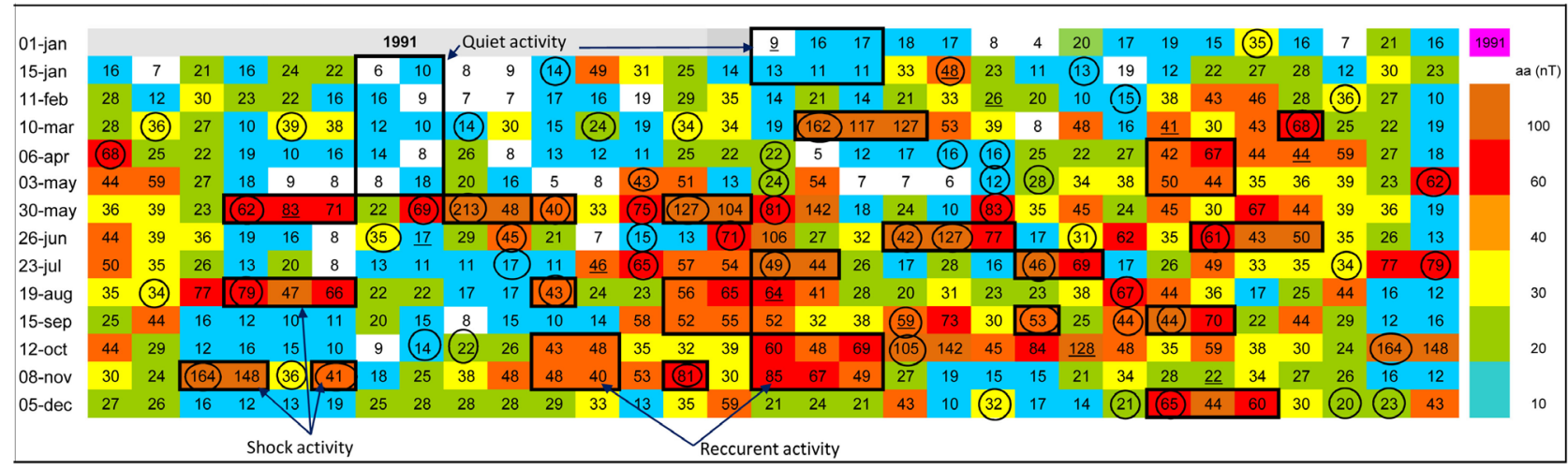

(b)

Figure 1. Pixel diagram using to determine geomagnetic activity classes by the criteria of the ancient classification or AC (b) and the new classification or NC (a). The blue and white color cases correspond to the quiet activity. The recurrent and the shock activities are those of the AC recurrent and shock events respectively. The NC recurrent events are those of the AC plus the corotating moderate activity (CMA) and its shock events correspond to those of the AC plus the cloud shock activity.

where $\Delta_{\text {occ }}$ is the gap of the occurrence of the concerning geomagnetic activity classes.

$\mathrm{GA}_{\text {occ }} / \mathrm{AC}$ is the occurrence of the concerning geomagnetic activity class in relation with the ancient classification

$\mathrm{GA}_{\text {occ }} / \mathrm{NC}$ is the occurrence of the concerning geomagnetic activity class in relation with the new classification

And 2) putting error bars in data graphs. We can note that error bar is obtained by using the Equation (2);

$$
\sigma=\sqrt{V}
$$

where $V$ is the variance defined by $V=\frac{1}{N} \sum_{i=1}^{N}\left(x_{i}-\bar{x}\right)^{2}$ with $\bar{x}$ mean value and $N$ the total number of observations for a particular dataset.

Secondly, the foF2 profiles (see Figure 2), linked to the nature, the strength or the absence of electric currents in E layer of ionosphere [36] [37] [38] [39] [40], are: Noon bite out or B profile characterized by a double peak (morning and evening) parted by a trough around midday; Reversed or R profile characterized by a single peak at evening; Morning pic or $M$ profile characterized by a single maximum at morning; Plateau or $\mathrm{P}$ profile characterized by an ionization plateau 


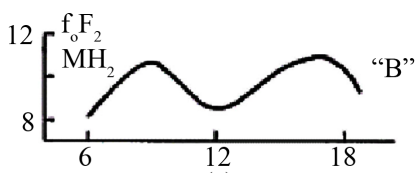

(a)

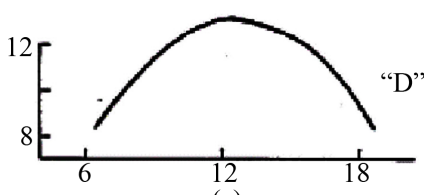

(c)

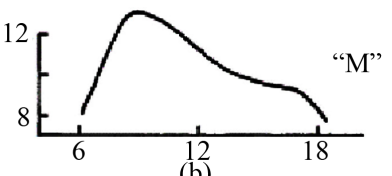

(b)

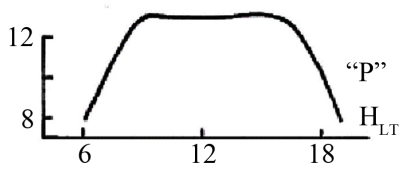

(d)

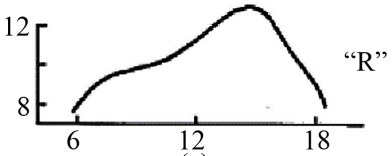

(e)

Figure 2. Faynot and Vila foF2 profile types for African equatorial region. (a) concerns B profile that expresses the signature of strong electrojet; (b) is M profile and exhibits the signature of mean electrojet; (c) is D and that of (d) is P profile. These two profiles characterized the absence of electrojet. (e) is $\mathrm{R}$ profile and expresses the signature of strong counter electrojet.

during daytime and Dome profile or D profile characterized by a single maximum around noon.

This morphological analysis of the profiles will reveal the difference between the equatorial ionosphere characteristics highlighted by the profiles obtained by the both classification methods. In fact those profiles express respectively a signature of a high electrojet, an important afternoon conter-electrojet, a moderate electrojet, a weak electrojet and an absence of electrojet. In addition [41]-[47] reviewed on mechanism responsible of equatorial trough at noon induced by electrodynamics $\boldsymbol{E} \times \boldsymbol{B}$ process.

In a third time, the quantitative analysis based on the appreciation of the difference between foF 2 values of the ancient classification and those from the new one will be made through the relative deviation of foF 2 defined by:

$$
\sigma_{\text {foF } 2}=\frac{\text { foF } 2_{\mathrm{AC}}-\text { foF } 2_{\mathrm{NC}}}{\text { foF } 2_{\mathrm{NC}}} \times 100
$$

where foF $2_{\mathrm{AC}}$ and $\mathrm{foF}_{\mathrm{NC}}$ are the foF 2 from the ancient geomagnetic activity classification and the new one respectively. $\Delta_{\mathrm{foF} 2}$ is the relative deviation with the following appreciation:

- $\sigma_{\mathrm{foF} 2}>10 \%$ the ancient classification overestimates the new standard classification value;

- $\sigma_{\mathrm{foF} 2}<-10 \%$ the ancient classification underestimates the new standard classification value;

$-10 \%<\sigma_{\mathrm{foF} 2}<10 \%$ both classifications are in agreement.

\section{Results and Discussion}

\subsection{Occurrences of the Geomagnetic Activities}

Figure 3 highlights the occurrence of the different geomagnetic activities 


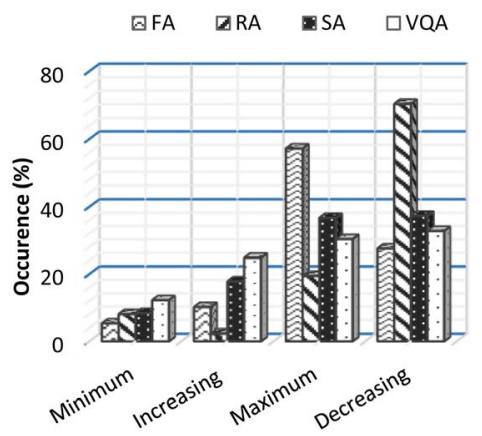

(a)

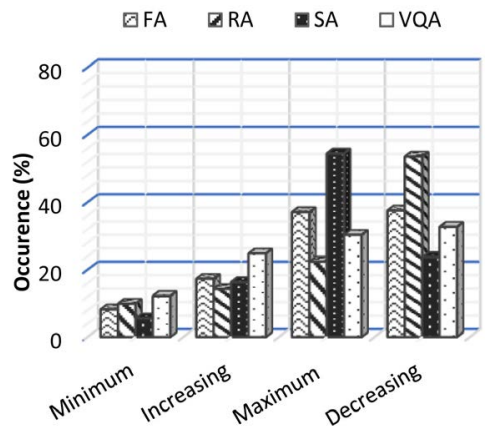

(b)

Figure 3. Comparison of the occurrence of the geomagnetic activity over solar cycle phases between the Ancient classification (a) and the new classification (panel b).

throughout solar cycle phases (panels "a" and "b"). The panels "a" and "b" concern the ancient classification (AC) and the new classification (NC) respectively.

For each solar cycle phase of both classifications, the diagram columns represent respectively the fluctuant, the recurrent, the shock and the very quiet activities. For the occurrence of the FA $\left(\mathrm{FA}_{\text {occ }}\right)$ over solar cycle phases, we have for the AC, $5.23 \% ; 10.10 \% ; 57.14 \%$ and $27.53 \%$ and for the NC, $8.21 \% ; 17.24 \%$; $37.03 \%$ and 37.52 , respectively for the minimum, the increasing, the maximum and the decreasing solar phases. Therefore, the FA occurs more during the maximum phase for $\mathrm{AC}$ and they occur more during maximum and decreasing phases with a value of occurrence roughly equal to $37 \%$ for the NC. Otherwise, for both classifications the FA occurs the least during the minimum phase. The maximum negative gap between both classifications occurrences is observed during the decreasing phase with a value of $\Delta_{\text {occ }}=-9.99 \%$ and the maximum positive occurrence is observed during the maximum phase with a value of $\Delta_{\text {occ }}=+20.11 \%$. Besides, for maximum phase, the FA's occurrence of the AC is greater than that of the NC; and we observe the opposite for the other solar cycle phases.

For the RA, we have for the AC, $8.0 \% ; 2.29 \% ; 19.43 \%$ and $70.29 \%$ and for the NC $9.88 \% ; 14.20 \% ; 22.38 \%$ and $53.55 \%$ respectively for the minimum, the increasing, the maximum and the decreasing solar phases. Therefore, the RA occurs more during the decreasing phase for both classifications. Otherwise, they occur the least during the minimum phase for the NC and the increasing phase for the AC. The AC's configuration is in good agreement with Legrand and Simon's [48] conclusion which suggests that the maxima and the minima of geomagnetic activity are observed respectively at solar decreasing and increasing phases. But the NC shows a different configuration with a minima of RA observed at solar minimum. The maximum negative gap between both classification occurrences is observed at increasing phase with a value of $\Delta_{\text {occ }}=-11.91 \%$ and the maximum positive gap of the occurrence is observed in decreasing phase with a value of $\Delta_{\text {occ }}=+16.74 \%$. Besides, for the decreasing phase, the RA's occurrence of the $\mathrm{AC}$ is greater than that of the $\mathrm{NC}$; and we observe the opposite 
for the other solar cycle phases.

In the case of the SA, we have for the AC, $8.32 \% ; 7.79 \%$; $36.62 \%$ and $37.27 \%$ and for the NC, $5.53 \% ; 16.26 \% ; 54.47 \%$ and $23.74 \%$ respectively for the minimum, the increasing, the maximum and the decreasing solar phases. Therefore, the SA occurs more during the maximum and the decreasing phases with a value of occurrence roughly equal to $37 \%$ and the less during increasing and minimum phase with a value of occurrence roughly equal to $8 \%$ for the AC. For the $\mathrm{NC}$, it occurs the most during the maximum phase and the least during solar minimum. The maximum negative gap between both classification occurrences is observed at maximum phase with a value $\Delta_{\text {occ }}=-17.85 \%$ and the maximum positive gap of the occurrence is observed in decreasing phase with a value $\Delta_{\text {occ }}=+8.53 \%$. Besides, for the decreasing phase with a value $\Delta_{\text {occ }}=+8.53 \%$, the SA's occurrence of the AC is greater than that of the NC. This observation is the same for the minimum phase. We observe the opposite for the increasing and maximum solar cycle phases.

\subsection{Profiles Comparison for Both Classifications throughout Solar Phases}

Figures 4-6 show the foF2 profiles during fluctuant activity (FA), recurrent activity (RA) and shock activity (SA) respectively. The panels "a", "b", "c" and "d" present the graph of the minimum, increasing, maximum and decreasing solar cycle phases respectively.

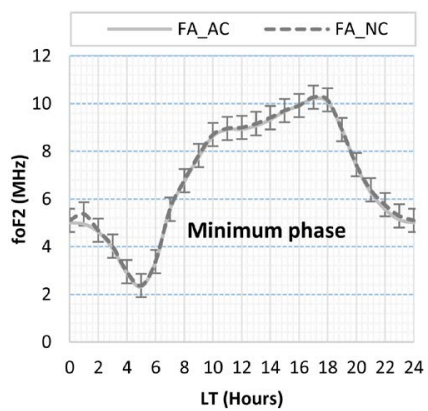

(a)

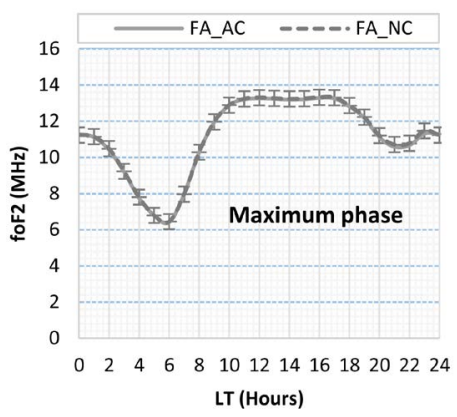

(c)

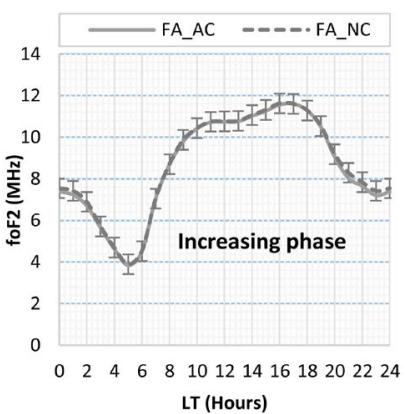

(b)

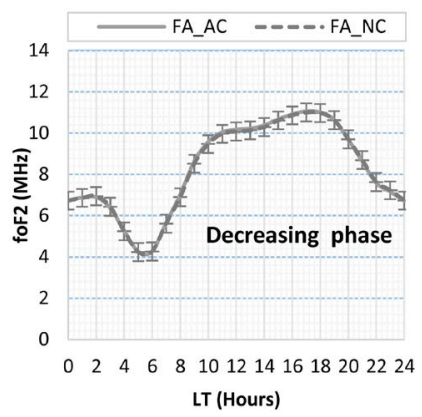

(d)

Figure 4. foF2 profiles during fluctuant geomagnetic activity (FA) during minimum, increasing, maximum and decreasing solar phases. The dashed curve is for the New classification (NC) and the solid one for the Ancient Classification (AC). 


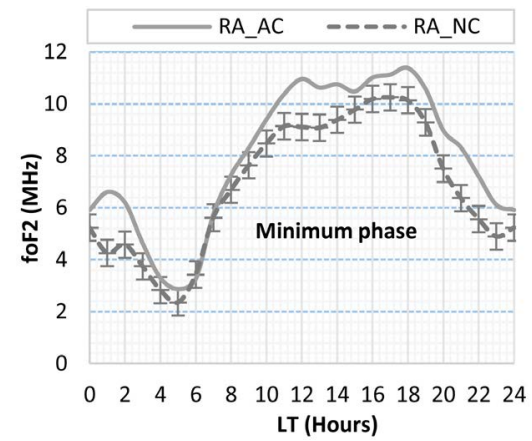

(a)

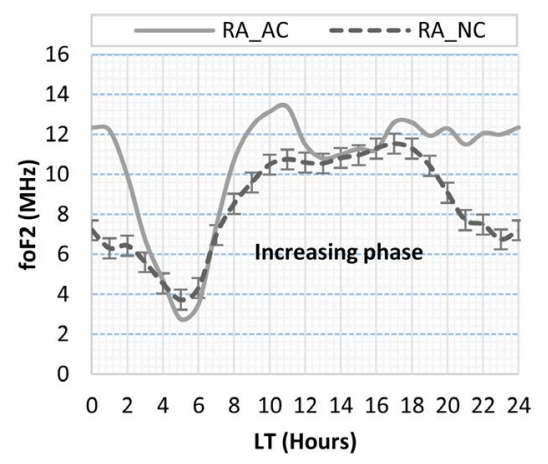

(c)

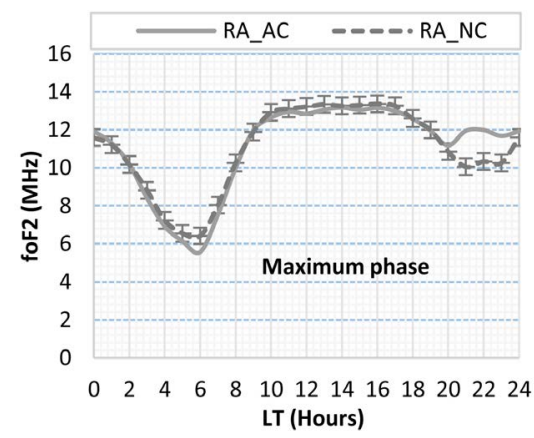

(e)

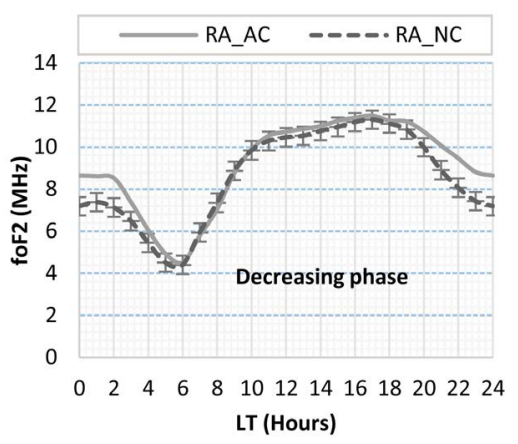

(g)

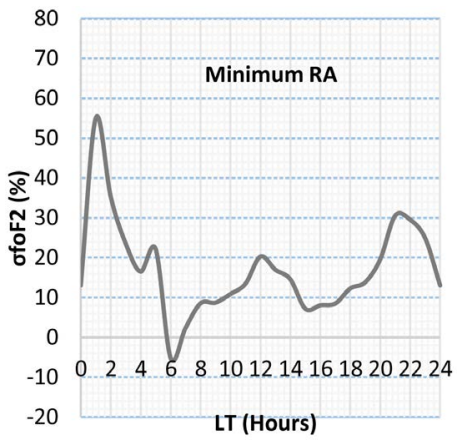

(b)

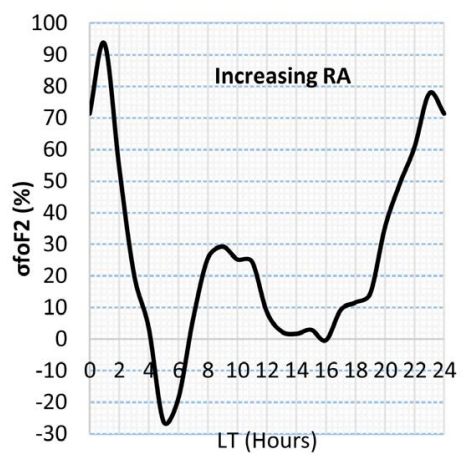

(d)

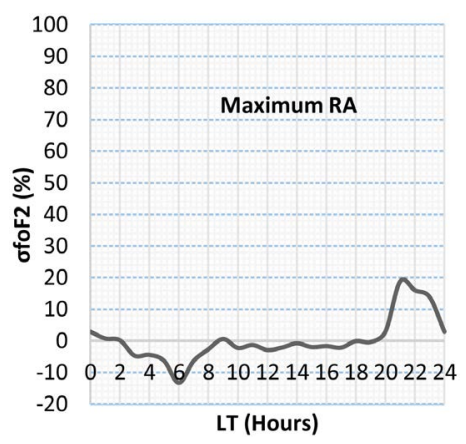

(f)

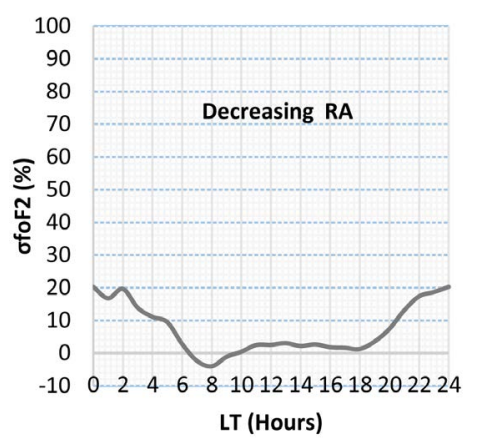

(h)

Figure 5. foF2 diurnal variation during recurrent activity (RA) throughout minimum (a), increasing (b), maximum (c) and decreasing (d) solar cycle phases. The dashed curve is for the New classification (NC) and the solid one for the Ancient Classification (AC). The left column is devoted for the foF2 diurnal variation profiles and the right one present the relative deviation percentage of foF2 between the RA foF2 values of the AC and that of the NC. 


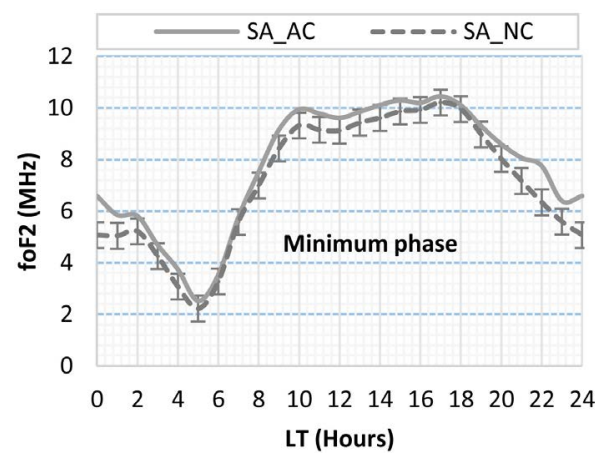

(a)

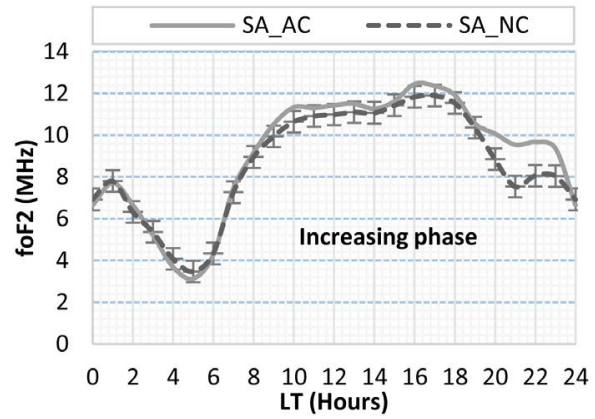

(c)

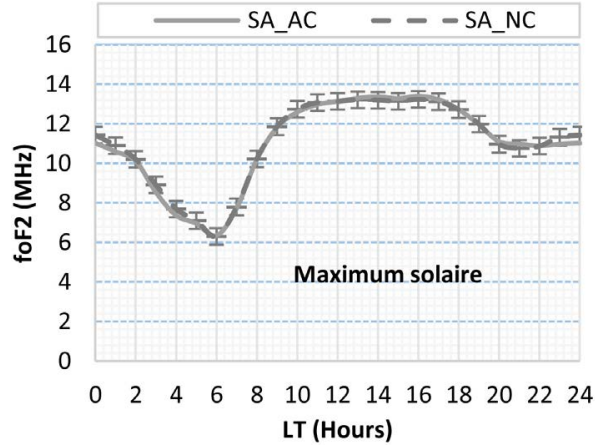

(e)

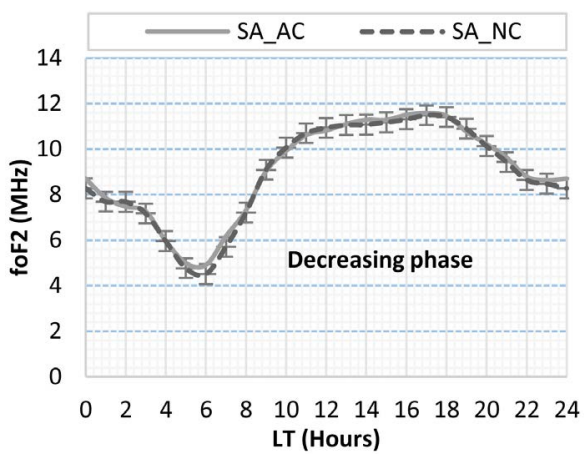

(g)

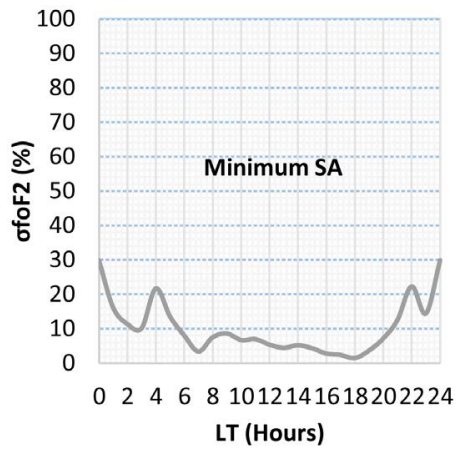

(b)

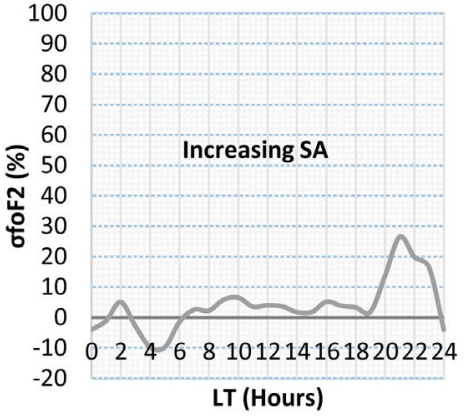

(d)

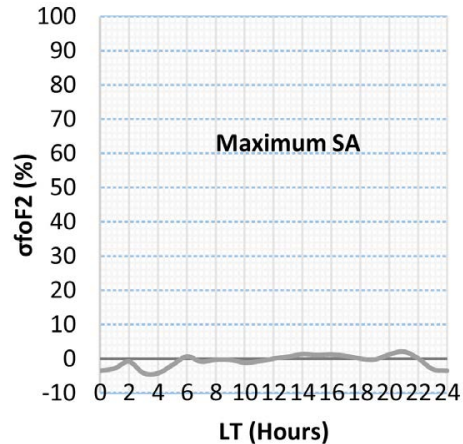

(f)

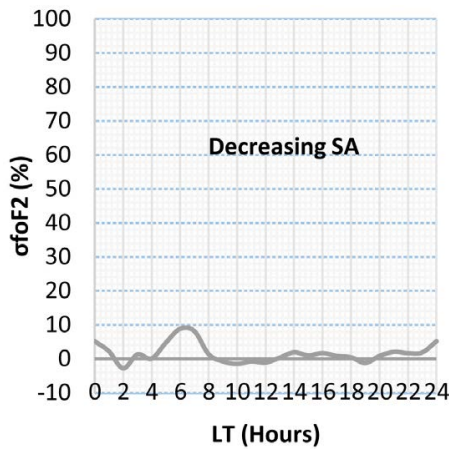

(h)

Figure 6. The same as Figure 5 but for shock activity.

Figure 4 shows that, during FA, both graphs show a "P" profile during maximum phase and an " $R$ " profile during the other solar cycle phases. Therefore, the FA is characterised by a weak electrojet during maximum phase, while it 
shows an important afternoon conter-electrojet in E layer of ionosphere during the other solar cycle phases considering the two classifications. Both classifications curves show the same shape and the same amplitude for all solar cycle phases with respect to error bars shown in NC graph; thus, for FA the foF2 profiles of both classifications don't show difference during all solar phases; it is so not important to estimate the relative deviation of foF2 during FA. This absence of difference between the two classifications can be explain by the fact that the FA is characterised by the unclear solar activity; perhaps the highlighting of the twenty percent (20\%) of the geomagnetic activity which are mixed in the unclear activities (remember that the NC explain about $80 \%$ of the solar activity in relation of the geomagnetic activity) will enable to make difference with the AC.

Figure 5 shows the foF2 values diurnal variation for the RA according to the two classification methods and the relative deviation percentage between both classifications. The panels "a" and " $d$ " highlight that the two classifications curves show an " $R$ " profile during the minimum and the decreasing phase. Therefore, the RA is characterised by the presence of an important afternoon conter-electrojet in the $\mathrm{E}$ layer of the ionosphere during minimum and decreasing phases considering the two classifications. Otherwise for the decreasing phase (panel "d"), we observe a difference between both classifications between 2100 LT to $0400 \mathrm{LT}$ with respect to error bars shown in NC graph and for the remaining daily time the two profiles were overlapped. The right column of the panel " $d$ " highlights this observation. In fact, we observe that the $\sigma_{\text {foF } 2}$ shows value: 1 ) within $\pm 10 \%$ between $0500 \mathrm{LT}$ to $2000 \mathrm{LT}, 2$ ) a value greater than $+10 \%$ between $2100 \mathrm{LT}$ to $0400 \mathrm{LT}$ with a maximum positive value of $+20.27 \% \mathrm{ob}$ served at $0000 \mathrm{LT}$ and 3) the negative values between $0700 \mathrm{LT}$ to $0900 \mathrm{LT}$ with a maximum negative value of $-4.04 \%$ observed at 0800 LT. And during minimum phase (panel "a"), the AC curve is almost always over the curve of the NC with respect to error bars shown in NC graph; but only before 0600 LT to before 0800 LT the two curves were overlapped and we observe a difference between the graphs of both classifications between 1000 LT to 0200 LT with respect to error bars shown in NC graph. The right column of this panel highlights this observation. In fact, the $\sigma_{\text {foF } 2}$ shows value within $\pm 10 \%$ between 0600 LT to $0900 \mathrm{LT}$ and $1500 \mathrm{LT}$ to $1700 \mathrm{LT}$. The maximum positive $\sigma_{\text {foF } 2}$ value is observed at 0100 LT with a value equal to $+55 \%$ and the single negative value, observed at 0600 LT and equal to $-5.15 \%$.

Panel " $c$ " shows that during the maximum phase, both curves show a " $P$ " profile for both classifications. Therefore, the RA is characterised by a weak electrojet in the E layer of the ionosphere during the maximum phase considering both classifications. Otherwise, we observe that the two graphs are overlapped during all the daytime; but both curves are different at 0600 LT and between 2000 LT to 2400 LT with respect to error bars shown in NC graph. Both curves showed a night time peak, with a peak of $12 \mathrm{MHz}$ observed at $2100 \mathrm{LT}$ (for the curve of AC) upper that of the NC (peak of $10 \mathrm{MHz}$ observed at $2200 \mathrm{LT}$ ). The right column of this panel highlights this observation. In fact, the $\sigma_{\mathrm{foF} 2}$ curve shows 
values within $\pm 10 \%$ between $0000 \mathrm{LT}$ to $0500 \mathrm{LT}$ and $0700 \mathrm{LT}$ to $2000 \mathrm{LT}$. The maximum positive $\sigma_{\mathrm{foF} 2}$ value is observed at $2100 \mathrm{LT}$ with a value equal to $+18.80 \%$ and the maximum negative value, observed at $0600 \mathrm{LT}$, is fairly equal to $-13.27 \%$.

At the increasing phase (panel " $b$ ") we observe a high difference between the two curves. The NC curve shows an " $R$ " profile while the AC profile shows a B profile with a trough around $1300 \mathrm{LT}$. Therefore, during increasing phase, the RA shows an important afternoon conter-electrojet for the NC while it is characterized by an intense electrojet for the AC. Otherwise, we observe that the AC graph is almost over that of the NC, except between $0500 \mathrm{LT}$ to $0600 \mathrm{LT}$ and at $1600 \mathrm{LT}$. We observe that the two graphs are nearly overlapped between $1300 \mathrm{LT}$ to $1600 \mathrm{LT}$; but both curves are different between $1800 \mathrm{LT}$ to $0300 \mathrm{LT}, 0500 \mathrm{LT}$ to $0600 \mathrm{LT}$ and $0800 \mathrm{LT}$ to $1100 \mathrm{LT}$ with respect to error bars shown in NC graph. The right column of this panel highlights this observation. In fact, the $\sigma_{\text {foF2 }}$ graph shows values within $\pm 10 \%$ at $0700 \mathrm{LT}$, at $0400 \mathrm{LT}$ and between 1200 LT to $1700 \mathrm{LT}$. The maximum positive $\sigma_{\mathrm{foF} 2}$ value is observed at $0100 \mathrm{LT}$ with a value equal to $+93.55 \%$ and the maximum negative value, observed at $0500 \mathrm{LT}$, is equal to $-26.10 \%$.

Figure 6 shows the foF2 values diurnal variation for the SA according to the two classification methods and the relative deviation percentage between both classifications. Panel "a" shows a "B" profile for both classifications graphs with an afternoon peak greater than the morning one. Therefore the SA of the two classifications is characterized by a high electrojet during minimum phase. Otherwise, we observe that the AC graph is almost over that of the NC. And the graph presents a difference between both classification's curves between $2100 \mathrm{LT}$ to $0500 \mathrm{LT}$ with respect to error bars shown in NC graph; but for the remaining daily time the two profiles are closely in a good agreement. The right column of this panel highlights this observation. In fact, the $\sigma_{\text {foF } 2}$ curve shows positive values within $[0 ;+10 \%]$ at around $0300 \mathrm{LT}$ and between $0500 \mathrm{LT}$ to $2100 \mathrm{LT}$. The maximum, observed at $0000 \mathrm{LT}$, is equal to $+29.84 \%$ and the minimum one, observed at $1800 \mathrm{LT}$, is equal to $+1.48 \%$

Panel " $b$ " presents an " $R$ " profile for both classifications graphs; but that of the AC is coupled with a trough observed at 1400 LT. Therefore, at solar increasing phase, the SA of the NC classification is characterized by an intense afternoon conter-electrojet while the one of the AC is characterized by a couple of an intense afternoon conter-electrojet and a late high electrojet, signature of a trough observed at $1400 \mathrm{LT}$. Otherwise, we observe a difference between both classification's curves between 2000 LT to 2300 LT with respect to error bars shown in NC graph; but for the remaining daily time the two profiles are closely in a good agreement. The right column of this panel highlights this observation. In fact, the $\sigma_{\text {foF } 2}$ curve shows values within $\pm 10 \%$ between 2000 LT 2300 LT. The maximum positive $\sigma_{\text {foF } 2}$ value is observed at $2100 \mathrm{LT}$ with a value equal to $+26.51 \%$ and the maximum negative value, observed at $0500 \mathrm{LT}$, is equal to $-9.84 \%$. 
At maximum phase (panel " $c$ "), for both classifications graphs, the SA profile is characterized by "P" profile which is a signature of a weak electrojet. We observe that the two curves are overlapped during all the daily time with respect to error bars shown in NC graph. The right column of this panel highlights this observation. In fact, the $\sigma_{\text {for } 2}$ curve shows values within $\pm 10 \%$ during all the daily time. Otherwise, we observe at 3.1) that the maximum negative gap between both classification occurrences for SA is observed at maximum phase with a value $\Delta_{\text {occ }}=-17.85 \%$. Therefore the Cloud Shock Activity CSA occurs more during solar maximum like have been found by [11] [49]. We can make the assumption that a high occurrence of CSA doesn't impact the electrodynamics of the ionosphere E layer.

Panel "d" presents an " $R$ " profile for both classifications graphs. Therefore, at solar decreasing phase, the both classification's SA are characterized by an intense afternoon conter-electrojet. We observe that the two curves are overlapped during all the daily time. The right column of this panel highlights this observation. In fact, the $\sigma_{\mathrm{foF} 2}$ curve shows values within $\pm 10 \%$ during all the daily time. Otherwise, we observe at 3.1) that the maximum positive gap between both classification occurrences for $\mathrm{SA}$ is observed at decreasing phase with a value $\Delta_{\text {occ }}=+13.53 \%$. Therefore, we can make the assumption that the high occurrence of cloud shock activity (CSA) doesn't impact the electrodynamics of the ionosphere E layer.

\section{Conclusion}

This paper shows that both classifications geomagnetic classes, at Dakar station, are different in terms of occurrences throughout solar cycle phases. It emerges that, for the RA, the higher the occurrences between two classes for a given phase are different, the more the profiles show difference and also the physical interpretation of the electrodynamics in the ionosphere layer. But the SA profiles of both classifications are closely similar during maximum and decreasing phase. In general, the $\mathrm{AC}$ and $\mathrm{NC}$ curves show different profiles during minimum and increasing phases for the RA and the SA. The FA profiles don't depend on the classification method at all.

\section{Acknowledgements}

The authors thank Brest Telecom of Bretagne for providing Dakar ionosonde data. Many thanks to ISGI data center for providing data center.

\section{Conflicts of Interest}

The authors declare no conflicts of interest regarding the publication of this paper.

\section{References}

[1] Legrand, J.-P. and Simon, P.A. (1989) Solar Cycle and Geomagnetic Activity: A Re- 
view for Geophysicists. I the Contributions to Geomagnetic Activity of Shock Waves and of the Solar Wind. Annales Geophysicae, 7, 565-578.

https://ui.adsabs.harvard.edu/abs/1989AnGeo...7..565L

[2] Richardson, I.G., Cane, H.V. and Cliver, E.W. (2002) Sources of Geomagnetic Activity during Nearly Three Solar Cycles (1972-2000). Journal of Geophysical Research: Space Physics, 107, SSH 8-1-SSH 8-13.

https://doi.org/10.1029/2001JA000504

[3] Richardson, I.G., Cliver, E.W. and Cane, H.V. (2000) Sources of Geomagnetic Activity over the Solar Cycle: Relative Importance of Coronal Mass Ejections, High-Speed Streams, and Slow Solar Wind. Journal of Geophysical Research: Space Physics, 105, 18203-18213. https://doi.org/10.1029/1999JA000400

[4] Richardson, I.G., Cliver, E.W. and Cane, H.V. (2001) Sources of Geomagnetic Storms for Solar Minimum and Maximum Conditions during 1972-2000. Geophysical Research Letters, 28, 2569-2572. https://doi.org/10.1029/2001GL013052

[5] Simon, P.A. and Legrand, J.P. (1989) Solar Cycle and Geomagnetic Activity: A Review for Geophysicists. Part 2. The Solar Sources of Geomagnetic Activity and Their Links with Sunspot Cycle Activity. Annales Geophysicae, 7, 579-594. https://ui.adsabs.harvard.edu/abs/1989AnGeo...7..579S

[6] Mayaud, P.N. (1971) Une mesure planétaire d'activité magnétique basée sur deux observatoires antipodaux. Annals of Geophysics, 27, 67-70.

[7] Mayaud, P.N. (1972) The AA Indices: A 100-Year Series Characterizing the Magnetic Activity. Journal of Geophysical Research, 77, 6870-6874.

https://doi.org/10.1029/JA077i034p06870

[8] Mayaud, P.N. (1973) A Hundred Year Series of Geomagnetic Data, 1868-1967: Indices AA, Storm Sudden Commencements. IAGA Bulletins, 33, 256.

[9] Mayaud, P.N. (1980) Derivation, Meaning, and Use of Geomagnetic Indices. Am. Geophys. Union Geophys. Monogr. Ser. 22, Washington DC. https://doi.org/10.1029/GM022

[10] Svalgaard, L. (1977) Geomagnetic Activity: Dependence on Solar Wind Parameters. In: Zirker, J.B., Ed., Coronal Holes and High Speed Wind Streams, Colorado Association University Press, Boulder, 371-441.

[11] Zerbo, J.-L., Amory-Mazaudier, C., Ouattara, F. and. Richardson, J.D. (2012) Solar Wind and Geomagnetism: Toward a Standard Classification of Geomagnetic Activity from 1868 to 2009. Annals of Geophysics, 30, 421-426. https://doi.org/10.5194/angeo-30-421-2012

[12] Diabaté, A., Ouattara, F. and Zerbo, J.-L. (2018) Annual and Diurnal Variabilities in the Critical Frequency (foF2) during Geomagnetic Fluctuating Activity over Solar Cycles 21 and 22 at Ouagadougou. Atmospheric and Climate Sciences, 8, 435-445. https://doi.org/10.4236/acs.2018.84029

[13] Diabaté, A., Zerbo, J.-L. and Ouattara, F. (2019) Variation of the foF2 Parameter during Fluctuating Activity: Prediction with IRI-2012 Compared to Measured Data from Ouagadougou Ionosonde Station during Solar Cycles 21 and 22. Vietnam Journal of Earth Sciences, 41, 59-68. https://doi.org/10.15625/0866-7187/41/1/13549

[14] Elias, A.G., Gnabahou, D.A. and Ouattara, F. (2014) The Effect of the Dip Equator Secular Displacement on Low Latitude foF2 Long Term Variations. 8th IAGA/ ICMA/CAWSES Workshop on Long-Term Changes and Trends in the Atmosphere, Cambridge, 27-31 July 2014, 27-31.

[15] Gnabahou, D.A., Elias, A.G. and Ouattara, F. (2013) Long-Term Trend of foF2 at a West African Equatorial Station Linked to Greenhouse Gas Increase and Dip Equa- 
tor Secular Displacement. Journal of Geophysical Research: Space Physics, 118, 3909-3913. https://doi.org/10.1002/jgra.50381

[16] Gnabahou, D.A., Ouattara, F., Nanéma, E. and Zougmoré, F. (2013) foF2 Diurnal Variability at African Equatorial Stations: Dip Equator Secular Displacement Effect. International Journal of Geosciences, 4, 1145. https://doi.org/10.4236/ijg.2013.48108

[17] Gyébré, A.M.F., Gnabahou, D.A. and Ouattara, F. (2018) The Geomagnetic Effects of Solar Activity as Measured at Ouagadougou Station. International Journal of Astronomy and Astrophysics, 8, 178. https://doi.org/10.4236/ijaa.2018.82013

[18] Kaboré, M., Zerbo, J.-L., Zoundi, C. and Ouattara, F. (2019) Variability of the Critical Frequency foF2 for Equatorial Regions during Solar Cycle's Minima and Maxima at Ouagadougou and Manila Stations. International Journal of Geo-sciences, 10, 833-844. https://doi.org/10.4236/ijg.2019.1010047

[19] Ouattara, F. and Amory-Mazaudier, C. (2012) Statistical Study of the Equatorial F Layer Critical Frequency at Ouagadougou during Solar Cycles 20, 21 and 22, Using Legrand and Simon's Classification of Geomagnetic Activity. EDP Sciences, 2, A19. https://doi.org/10.1051/swsc/2012019

[20] Ouattara, F., Amory-Mazaudier, C., Fleury, R., Lassudrie-Duchesne, P., Vila, P. and Petitdidier, M. (2009) West African Equatorial Ionospheric Parameters Climatology Based on Ouagadougou Ionosonde Station Data from June 1966 to February 1998. Annals of Geophysics, 27, 2503-2514. https://doi.org/10.5194/angeo-27-2503-2009

[21] Ouattara, F., Gnabahou, D.A. and Amory-Mazaudier, C. (2012) Seasonal, Diurnal, and Solar-Cycle Variations of Electron Density at Two West Africa Equatorial Ionization Anomaly Stations. International Journal of Geophysics, 2012, Article ID: 640463. https://doi.org/10.1155/2012/640463

[22] Sawadogo, W.E., Zerbo, J.-L., Ali, M.N. and Ouattara, F. (2019) Diurnal Variation of F2-Layer Critical Frequency under Solar Activity Recurrent Conditions during Solar Cycles 21 and 22 at Ouagadougou Station: Prediction with IRI-2012. Scientific Research and Essays, 14, 111-118.

[23] Thiam, N., Ouattara, F., Gnabahou, D.A., Amory-Mazaudier, C., Fleury, R. and Duchesne, P.L. (2012) Variation de la Fréquence Critique de la Couche F2 (foF2) de la Station de Dakar avec le Cycle Solaire. Journal of Sciences, 11, 16-20.

[24] Ouattara, F. (2009) Relationship between Geomagnetic Classes' Activity Phases and Their Occurrence during the Sunspot Cycle. Annals of Geophysics, 52, 107-116.

[25] Ouattara, F. and Amory-Mazaudier, C. (2008) Solar-Geomagnetic Activity and Aa Indices toward a Standard. Journal of Atmospheric and Solar-Terrestrial Physics, 71, 1736-1748. https://doi.org/10.1016/j.jastp.2008.05.001

[26] Ouattara, F. and Amory-Mazaudier, C. (2009) Solar-Geomagnetic Activity and Aa Indices toward a Standard Classification. Journal of Atmospheric and Solar- Terrestrial Physics, 71, 1736-1748. https://doi.org/10.1016/j.jastp.2008.05.001

[27] Zerbo, J.-L. (2012) Activité solaire, vent solaire, géomagnétisme et ionosphère équatoriale.

[28] Zerbo, J.-L., Ouattara, F., Amory-Mazaudier, C., Legrand, J.-P. and Richardson, J.D. (2013) Solar Activity, Solar Wind and Geomagnetic Signatures. Atmospheric and Climate Science, 3, 610-617. https://doi.org/10.4236/acs.2013.34063

[29] Zerbo, J.-L., Amory-Mazaudier, C. and Ouattara, F. (2013) Solar Wind Fluctuations and Solar Activity Long-Term Swing: 1963-2012. Proceedings of the International Astronomical Union, 8, 473-474. https://doi.org/10.1017/S1743921313011617 
[30] Gnabahou, D.A. and Ouattara, F. (2012) Ionosphere Variability from 1957 to 1981 at Djibouti Station. European Journal of Scientific Research, 73, 382-390.

[31] Ouattara, F. and Zerbo, J.-L. (2011) Ouagadougou Station F2 Layer Parameters, Yearly and Seasonal Variations during Severe Geomagnetic Storms Generated by Coronal Mass Ejections (CMEs) and Fluctuating Wind Streams. International Journal of Physical Sciences, 6, 4854-4860.

[32] Ouattara, F., Amory-Mazaudier, C., Menvielle, M., Simon, P. and Legrand, J.-P. (2009) On the Long Term Change in the Geomagnetic Activity during the 20th Century. Annals of Geophysics, 27, 2045-2051.

http://www.ann-geophys.net/27/2045/2009

https://doi.org/10.5194/angeo-27-2045-2009

[33] Guibula, K., Ouattara, F. and Gnabahou, D.A. (2018) foF2 Seasonal Asymmetry Time Variation at Korhogo Station from 1992 to 2002. International Journal of Geosciences, 9, 207. https://doi.org/10.4236/ijg.2018.94013

[34] Nanéma, E., Konaté, M. and Ouattara, F. (2019) Peak of Electron Density in F2-Layer Parameters Variability at Quiet Days on Solar Minimum. Journal of Modern Physics, 10, 302-309. https://doi.org/10.4236/jmp.2019.103021

[35] Faynot, J.M. and Vila, P. (1979) F Region Strata at the Magnetic Equator. Annals of Geophysics, 35, 1-9. https://ui.adsabs.harvard.edu/abs/1979AnG....35....1F

[36] Acharya, R., Roy, B., Sivaraman, M.R. and Dasgupta, A. (2010) An Empirical Relation of Daytime Equatorial Total Electron Content with Equatorial Electrojet in the Indian Zone. Journal of Atmospheric and Solar-Terrestrial Physics, 72, 774-780. https://doi.org/10.1016/j.jastp.2010.03.023

[37] Acharya, R., Roy, B., Sivaraman, M.R. and Dasgupta, A. (2011) On Conformity of the EEJ Based Ionospheric Model to the Fountain Effect and Resulting Improvements. Journal of Atmospheric and Solar-Terrestrial Physics, 73, 779-784. https://doi.org/10.1016/j.jastp.2011.01.011

[38] Dunford, E. (1967) The Relationship between the Ionospheric Equatorial Anomaly and the E-Region Current System. Journal of Atmospheric and Terrestrial Physics, 29, 1489-1498. https://doi.org/10.1016/0021-9169(67)90102-X

[39] Vassal, J. (1982) Electrojet, contre-électrojet et région F à Sarh (Tchad). Géophysique, 19, 3-9.

[40] Vassal, J. (1982) La variation du champ magnétique et ses relations avec I'électrojet équatorial au Sénégal Oriental. Annals of Geophysics, 38, 347-355. https://core.ac.uk/reader/39875346

[41] Fejer, B.G. (1981) The Equatorial Ionospheric Electric Fields. Journal of Atmospheric and Terrestrial Physics, 43, 377-386. https://doi.org/10.1016/0021-9169(81)90101-X

[42] Fejer, B.G., Farley, D.T., Woodman, R.F. and Calderon, C. (1979) Dependence of Equatorial F Region Vertical Drifts on Season and Solar Cycle. Journal of Geophysical Research: Space Physics, 84, 5792-5796. https://doi.org/10.1029/JA084iA10p05792

[43] Fejer, B.G., Farley, D.T., Gonzales, C.A., Woodman, R.F. and Calderon, C. (1981) F Region East-West Drifts at Jicamarca. Journal of Geophysical Research: Space Physics, 86, 215-218. https://doi.org/10.1029/JA086iA01p00215

[44] Fejer, B.G., De Paula, E.R., Heelis, R.A. and Hanson, W.B. (1995) Global Equatorial Ionospheric Vertical Plasma Drifts. Journal of Geophysical Research, 100, 57695776. https://doi.org/10.1029/94JA03240 
[45] Abdu, M.A., Bittencourt, J.A. and Batista, I.S. (1981) Magnetic Declination Control of the Equatorial F Region Dynamo Electric Field Development and Spread F. Journal of Geophysical Research: Space Physics, 86, 11443-11446. https://doi.org/10.1029/JA086iA13p11443

[46] Abdu, M.A., Batista, I.S. and Sobral, J.H.A. (1992) A New Aspect of Magnetic Declination Control of Equatorial Spread F and F Region Dynamo. Journal of Geophysical Research: Space Physics, 97, 14897-14904.

https://doi.org/10.1029/92JA00826

[47] Farley, D.T., Bonelli, E., Fejer, B.G. and Larsen, M.F. (1986) The Prereversal Enhancement of the Zonal Electric Field in the Equatorial Ionosphere. Journal of Geophysical Research: Space Physics, 91, 13723-13728.

https://doi.org/10.1029/JA091iA12p13723

[48] Legrand, J.-P. and Simon, P.A. (1985) Some Solar Cycle Phenomena Related to the Geomagnetic Activity from 1868 to 1980, I. The Shock Events, or the Interplanetary Expansion of the Toroidal Field. Astronomy and Astrophysics, 152, 199-204. https://ui.adsabs.harvard.edu/abs/1985A\&A...152...199L

[49] Wu, C.-C., Lepping, R.P. and Gopalswamy, N. (2006) Relationships among Geomagnetic Clouds, CMEs and Geomagnetic Storms. Solar Physics, 239, 449-460. https://doi.org/10.1007/s11207-006-0037-1 